\title{
Intravesical dual PI3K/mTOR complex 1/2 inhibitor NVP-BEZ235 therapy in an orthotopic bladder cancer model
}

\author{
MASASHI MATSUSHIMA, EIJI KIKUCHI, KAZUHIRO MATSUMOTO, SEIYA HATTORI, \\ TOSHIKAZU TAKEDA, TAKEO KOSAKA, AKIRA MIYAJIMA and MOTOTSUGU OYA \\ Department of Urology, Keio University School of Medicine, Shinjuku-ku, Tokyo 160-8582, Japan
}

Received February 27, 2015; Accepted April 14, 2015

DOI: $10.3892 /$ ijo.2015.2995

\begin{abstract}
NVP-BEZ235 is an inhibitor of both phosphatidylinositol 3-kinase (PI3K) and mammalian target of rapamycin complex $1 / 2$ (mTORC1/2), and its antitumor activity is expected to be higher than that of mTORC1 inhibitors because it inhibits the upregulation of pAkt through mTORC2. We examined the efficacy of intravesical NVP-BEZ235 therapy in the treatment of bladder cancer using an orthotopic bladder cancer model. The cytotoxic effects of various concentrations of NVP-BEZ235 in MBT-2 cells were examined using a WST assay. The expression of pAkt, pS6 and p4EBP1 was evaluated in MBT-2 cells treated with NVP-BEZ235 using western blotting. Orthotopic models were established by implanting MBT- 2 cells into the bladders of female $\mathrm{C} 3 \mathrm{H} / \mathrm{He}$ mice. We assigned $\mathrm{C} 3 \mathrm{H} / \mathrm{He}$ mice to 2 groups: a control group treated with vehicle control $(n=15)$, and a group intravesically administered $40 \mu \mathrm{M}(18.78 \mathrm{mg} / \mathrm{l})$ of NVP-BEZ235 ( $n=15)$. NVP-BEZ235 inhibited the viability of MBT-2 cells in a dose-dependent manner. Furthermore, the expression of pAkt, pS6, and p4EBP1 was inhibited in NVP-BEZ235-treated MBT-2 cells. Bladder weights were significantly lower in the NVP-BEZ235-treated group than in the control group $(\mathrm{P}<0.05)$. An analysis of the tumor tissues revealed that the NVP-BEZ235 treatment strongly reduced pAkt, pS6 and p4EBP1 levels. An immunohistochemical
\end{abstract}

Correspondence to: Dr Eiji Kikuchi, Department of Urology, Keio University School of Medicine, 35 Shinanomachi, Shinjuku-ku, Tokyo 160-8582, Japan

E-mail: eiji-k@kb3.so-net.ne.jp

Abbreviations: TURBT, transurethral resection of the bladder tumor; BCG, bacillus Calmette-Guerin; NMIBC, non-muscle-invasive bladder cancer; PI3K, phosphatidylinositol 3-kinase; mTOR, mammalian target of rapamycin; mTORC1, mTOR complex 1; mTORC2, mTOR complex 2; UC, urothelial carcinoma; pAkt, phospho-Akt; pS6, phospho-S6 ribosomal protein; p4EBP1, phospho-4E-BP1; RPMI, Roswell Park Memorial Institute; WST, water-soluble tetrazolium; TBS, Tris-buffered saline; CSS, cancer-specific survival

Key words: bladder cancer, intravesical therapy, mTOR, novel antitumor agents, NVP-BEZ235 analysis showed that NVP-BEZ235 significantly inhibited the expression of pS6. Intravesically administered NVP-BEZ235 exerted significant antitumor effects in the orthotopic bladder cancer model by inhibiting the PI3K/Akt/mTOR pathway. The intravesical instillation of a dual $\mathrm{PI} 3 \mathrm{~K} / \mathrm{mTORC} 1 / 2$ inhibitor may represent a novel therapy for the treatment of bladder cancer.

\section{Introduction}

Between 70 and $80 \%$ of bladder tumor cases are non-muscleinvasive tumors confined to the mucosa. Patients with this type of tumor undergo conservative treatment consisting of transurethral resection of the bladder tumor (TURBT) followed by intravesical adjuvant treatment $(1,2)$. Intravesical immunotherapy with bacillus Calmette-Guerin (BCG) is the most effective adjuvant therapy for intermediate or high risk non-muscle-invasive bladder cancer (NMIBC) (3). However, the recurrence rate of NMIBCs is $60-70 \%$, and $30 \%$ of recurrent tumors eventually progress to muscle invasive tumors (3). Moreover, the intravesical instillation of BCG can lead to non-specific inflammation in the bladder and sometimes result in side effects of sufficient severity to cause the treatment to be discontinued (4). Thus, new strategies and therapeutic agents with superior antitumor effects to those of conventional intravesical therapy with BCG are highly desirable for the treatment of NMIBC.

The phosphatidylinositol 3-kinase (PI3K)/Akt/mammalian target of rapamycin (mTOR) signaling pathway has been linked to tumorigenesis in many tissues $(5,6)$. The PI3K/Akt/ mTOR pathway controls processes involved in tumor cell growth, proliferation and survival after DNA damage (7). The kinase mTOR consists of mTOR complex 1 (mTORC1) and mTOR complex 2 (mTORC2), which are two functionally distinct multiprotein complexes (8). mTORC1 inhibitors, such as RAD001, are known to have potent preclinical activities with respect to a wide variety of cancers, and RAD001 has been clinically approved as a treatment for renal cancer $(9,10)$. In urothelial carcinoma (UC), preclinical studies have shown that mTORC1 inhibitors exhibit antitumor effects both in vitro and in vivo (11-14).

NVP-BEZ235 is a dual PI3K and mTORC1/2 inhibitor, the antitumor activity of which is expected to be higher than that of mTORC1 inhibitors in various human cancers because 
it inhibits the upregulation of phospho-Akt (pAkt) through mTORC2 (15). Preclinical studies demonstrated the antitumor activity of NVP-BEZ235 in various models $(16,17)$. However, the efficacy of dual PI3K/mTORC1/2 inhibitors has not yet been examined in bladder cancer in vivo.

The orthotopic bladder cancer model is effective for the evaluation of new intravesical agents against bladder cancer. In our model, a high incidence of bladder cancer was observed after the simple instillation of MBT-2 cell suspensions into the bladders of syngeneic hosts (18). IL-2, IL-12 and IL-15 intravesical gene therapies have previously been reported by our group using this model (19-21).

We here examined the cytotoxic effects of the dual PI3K and mTORC1/2 inhibitor NVP-BEZ235 in vitro and determined whether intravesically administered NVP-BEZ235 exhibited therapeutic effects in a MBT-2 murine orthotopic bladder cancer model through inhibition of the PI3K/Akt/ mTOR pathway.

\section{Materials and methods}

Reagents. Rabbit monoclonal antibodies for pAkt (Ser473), phospho-S6 ribosomal protein (pS6) (Ser235/236) (D57.2.2E), and phospho-4E-BP1 (p4EBP1) (Thr37/46) were obtained from Cell Signaling Technology (Boston, MA, USA), and a mouse monoclonal antibody for $\beta$-actin was purchased from Sigma-Aldrich (St. Louis, MO, USA). NVP-BEZ235 was kindly provided by Novartis (Basel, Switzerland) via a material transfer agreement.

Cell line and animals. The MBT-2 murine bladder cancer cell line was provided by Dr T. Ratliff (University of Iowa, Iowa City, IA, USA). MBT-2 was established from N-[4-(5-nitro-2furyl)-2-thiazolyl]-formamide-induced urothelial carcinoma of the bladder removed from a female $\mathrm{C} 3 \mathrm{H} / \mathrm{He}$ mouse. Cells were maintained in Roswell Park Memorial Institute (RPMI)-1640 medium containing $10 \%$ heat-inactivated fetal bovine serum at $37^{\circ} \mathrm{C}$ in a humidified $5 \% \mathrm{CO}_{2}$ atmosphere. Female $\mathrm{C} 3 \mathrm{H} / \mathrm{He}$ mice (8 weeks old) were purchased from Sankyo Laboratory Service Co. (Tokyo, Japan). The Animal Care Committee of Keio University approved all the procedures in this study involving animals and their care in accordance with institutional and Japanese government guidelines for animal experiments.

Cytotoxic assay in vitro. MBT-2 cells were seeded on 96-well plates in a volume of $1 \times 10^{4}$ cells $/ 100 \mu \mathrm{l} /$ well culture medium and incubated overnight at $37^{\circ} \mathrm{C}$ under $5 \% \mathrm{CO}_{2}$ in a humidified incubator. MBT- 2 cells were treated with selected concentrations of NVP-BEZ235 for 12, 24 or $48 \mathrm{~h}$. At the end of the predetermined incubation periods, the cells in each well were counted in triplicate with a Premix water-soluble tetrazolium (WST)-1 Cell Proliferation Assay System (Kyoto, Japan). Each well was treated with Premix WST-1 (10 $\mu \mathrm{l} /$ well) and the plates were further incubated for $60 \mathrm{~min}$. A microplate reader was then used to measure absorbance at $450 \mathrm{~nm}$ with a reference wavelength of $650 \mathrm{~nm}$. Data were expressed as the percentage of surviving cells relative to that of a control.

Cell extraction and western blot analysis. To obtain whole-cell extracts, we used RIPA buffer consisting of $50 \mathrm{mM}$ Tris-HCl
(pH 7.5), protease inhibitors, $1 \%$ NP-40, $0.5 \%$ deoxycholate, $0.1 \%$ sodium dodecyl sulfate, and $150 \mathrm{mM} \mathrm{NaCl}$. In western blotting, $50 \mu \mathrm{g}$ of total protein was separated using sodium dodecyl sulfate-polyacrylamide gel electrophoresis on a $12.5 \%$ acrylamide gel and then transferred to a nitrocellulose membrane. The membrane was blocked for $1 \mathrm{~h}$ in Tris-buffered saline (TBS) containing 5\% PhosphoBlocker ${ }^{\mathrm{TM}}$ Blocking Reagent (Cell Biolabs, Inc. San Diego, CA, USA) and 0.2\% Tween-20. To detect pAkt, pS6, p4EBP1, and $\beta$-actin, anti-pAkt (Ser473, Cell Signaling Technology), anti-pS6 (Ser235/236, D57.2.2E, Cell Signaling Technology), anti-p4EBP1 (Thr37/46, Cell Signaling Technology), and anti- $\beta$-actin (Sigma-Aldrich) antibodies were incubated with the membranes overnight at $4^{\circ} \mathrm{C}$. The membranes were then washed for 3-5 min in TBS with $0.2 \%$ Tween-20 and then incubated in a peroxidaselabeled secondary antibody (Dako, Glostrup, Denmark) for $1 \mathrm{~h}$. Membranes were then washed again and analyzed after visualization by enhanced chemiluminescence reagents with the ECL Plus ${ }^{\mathrm{TM}}$ Western Blotting Detection System (GE Healthcare UK Ltd., Buckinghamshire, UK). The intensities of the signals were quantified using the LAS 4000 system (Fujifilm, Tokyo, Japan).

Establishment of an orthotopic MBT-2 bladder cancer model. An orthotopic bladder cancer model was created by the intravesical implantation of MBT-2 cells, as previously described (18). Briefly, mice were anesthetized with an intraperitoneal injection of pentobarbital sodium $(1.5 \mathrm{mg} / 200 \mu \mathrm{l})$ and mild pressure was applied to the abdomen to obtain urine samples evacuated from the bladder. MBT- 2 cells $\left(5 \times 10^{5}\right.$ in a 50- $\mu 1$ suspension of serum-free RPMI-1640 medium) were injected into the bladder through a 24-gauge Teflon-coated catheter that had been introduced into the lumen of the bladder through the urethra. The catheter was then removed, and, to prevent the voiding of MBT-2 cells, the urethra was tied with 4-0 silk thread for $2 \mathrm{~h}$. We previously investigated serial tumor growth in this orthotopic MBT-2 bladder tumor model and found that very small superficial tumors had been established 3 days after the implantation of MBT- 2 cell suspensions and gradually grew into visible masses (18). All the procedures were tolerated well, and none of the mice died postoperatively.

Intravesical NVP-BEZ235 therapy in an orthotopic bladder cancer model. Regarding intravesical administration, $100 \mu \mathrm{l}$ of PBS or $40 \mu \mathrm{M}(18.78 \mathrm{mg} / \mathrm{l})$ of NVP-BEZ235 in $100 \mu \mathrm{l}$ of PBS was instilled transurethrally ( $\mathrm{n}=15$ mice per group). The NVP-BEZ235 and PBS instillation experiments were started 5 days after tumor implantation and were carried out 5 times at 3-day intervals (i.e., on days 5, 8, 11, 14 and 17). Transurethral injections were carried out under anesthesia induced by an intraperitoneal injection of pentobarbital sodium. All the surviving mice were sacrificed on day 21 and necropsied. To assess the growth of bladder tumors, the weights of the bladders were measured. Additionally, to assess the potential toxicity of intravesical NVP-BEZ235 therapy, we examined the histological appearances of the major organs, including the heart, lung, liver, and kidney. The serum concentrations of albumin, total bilirubin, creatinine, and alanine aminotransferase were also determined. 

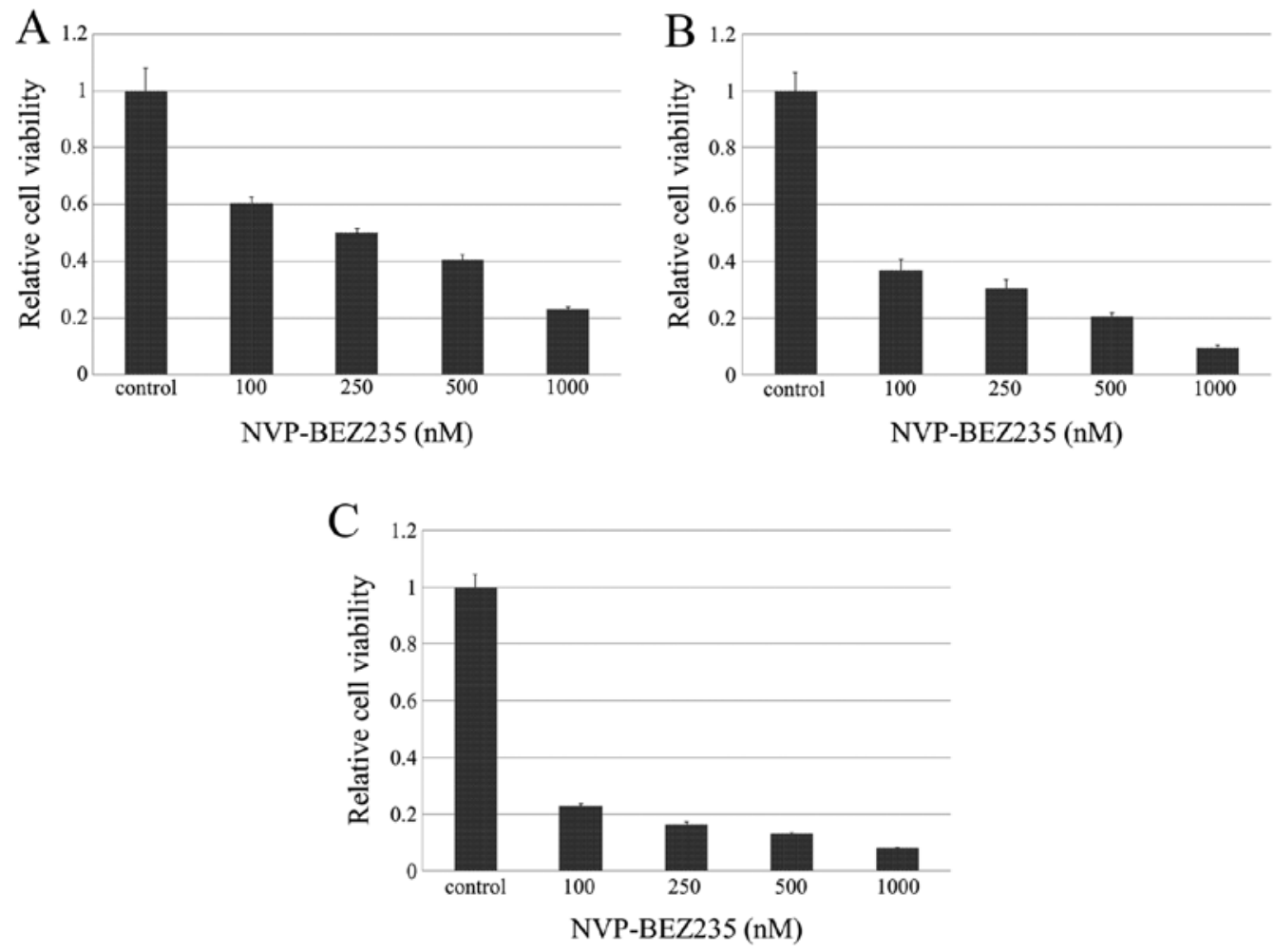

Figure 1. (A-C) MBT-2 cells were treated with selected concentrations of NVP-BEZ235 for 12 (A), 24 (B) or $48 \mathrm{~h}$ (C). The inhibitory effects of NVP-BEZ235 on MBT-2 cell viability were examined using a WST assay. The inhibition of cell growth was greater in NVP-BEZ235-treated cells than in untreated cells, and this occurred in a dose-dependent manner.

Analysis of MBT-2 tumor extracts from mice treated with $N V P-B E Z 235$. A second set of in vivo experiments was performed to evaluate changes in the PI3K/Akt/mTOR pathway after the intravesical administration of NVP-BEZ235 in tumors. Mice treated with NVP-BEZ235 $(40 \mu \mathrm{M}, 18.78 \mathrm{mg} / \mathrm{l})$ or vehicle control were sacrificed $12 \mathrm{~h}$ after the last dose (on day 18) ( $\mathrm{n}=3$ mice per group), whole tumor extracts in most parts of the bladder were obtained using RIPA buffer, and the protein expression of pAkt, pS6 and p4EBP1 was evaluated by western blotting, as described above. Furthermore, some of the tumors in the bladders of mice treated with NVP-BEZ235 $(40 \mu \mathrm{M}, 18.78 \mathrm{mg} / \mathrm{l})$ or vehicle control were immunohistochemically evaluated for the expression of the pS6 protein. Formalin-fixed, paraffin-embedded sections $(4 \mu \mathrm{m})$ were analyzed. Antigen retrieval with citric acid ( $\mathrm{pH} 6.0$ ) was carried out, and then endogenous peroxidase activity was blocked by a 20 -min treatment with $0.3 \%$ hydrogen peroxide. Sections were incubated for $15 \mathrm{~min}$ in a blocking solution (Protein Block Serum-Free Ready-to-use, Dako) and were then incubated with an antibody specific for pS6 (dilution 1:100) (Ser235/236, D57.2.2E, Cell Signaling Technology) for $2 \mathrm{~h}$. Slides were incubated for $30 \mathrm{~min}$ with secondary antibodies conjugated to a peroxidase-labeled dextran polymer. Visualization of the immunoreaction was achieved using diaminobenzidine followed by counterstaining with $10 \%$ hematoxylin.

Statistical analysis. All values are presented as the mean \pm standard deviation (SD). The significance of differences between groups was assessed using ANOVA and/or the Student's t-test, as appropriate. Significance was determined as $\mathrm{P}<0.05$. These analyses were performed using $\mathrm{IBM}^{\circledR}$ SPSS $^{\circledR}$ Statistics Version 21 (International Business Machines Corp., Armonk, NY, USA).

\section{Results}

Cytotoxic effects of NVP-BEZ235 on MBT-2 cells in vitro. We examined the cytotoxic effects of NVP-BEZ235 on MBT-2 cells in vitro (Fig. 1). After being exposed to NVP-BEZ235 at concentrations of $100,250,500$ and $1000 \mathrm{nM}$ for $12 \mathrm{~h}$, the mean relative cell viabilities to vehicle were $60.4 \pm 9.1 \%, 50.0 \pm 5.3 \%$, $40.4 \pm 7.5 \%$, and $23.0 \pm 3.5 \%$, respectively. The inhibition of cell growth was significantly greater in cells treated at any concentration of NVP-BEZ235 than in those treated with vehicle control after $12 \mathrm{~h}$ of exposure to NVP-BEZ235 in a dosedependent manner. Equivalent or stronger cytotoxic effects were observed after 24 and $48 \mathrm{~h}$ of exposure to NVP-BEZ235.

NVP-BEZ235 inhibited pAkt, pS6, and p4EBP1 in MBT-2 cells in vitro. To assess the inhibitory effect of NVP-BEZ235 on the PI3K/Akt/mTOR signaling pathway, we evaluated the protein expression of pAkt, pS6, and p4EBP1 in MBT-2 cells treated with or without NVP-BEZ235 by western blotting. The expression of pS6 in MBT-2 cells was significantly inhibited by NVP-BEZ235 at a dose of $100 \mathrm{nM}$ or higher (Fig. 2A). The expression of pAkt and p4EBP1 was also significantly inhibited by NVP-BEZ235 in a dose-dependent manner (Fig. 2A). The expression of pS6, pAkt, and p4EBP1 was inhibited in cells exposed to NVP-BEZ235 for $12 \mathrm{~h}$, and these inhibitory effects persisted for $24 \mathrm{~h}$ (Fig. 2B). 
A

pAKT
pS6
p4EBP1
$\beta$-actin

NVP-BEZ235
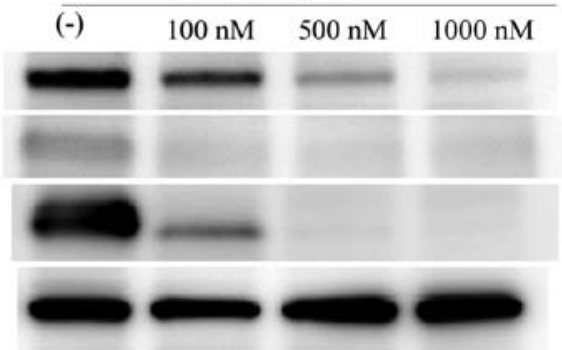

B

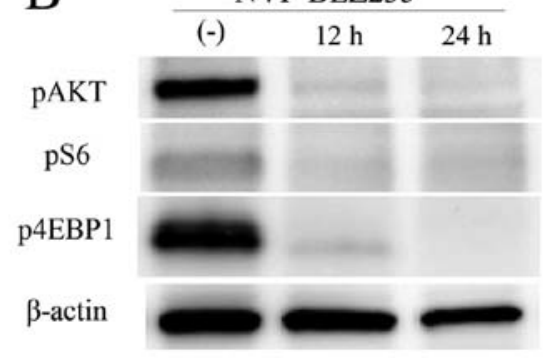

Figure 2. Western blot analysis of the protein expression of pAkt, pS6, and p4EBP1 following the treatment with NVP-BEZ235 in vitro. The protein expression of pAkt, pS6, p4EBP1 and $\beta$-actin in MBT-2 cells following the exposure to NVP-BEZ235 was determined using a western blot analysis with specific antibodies. $\beta$-actin was used as a loading control. (A) MBT- 2 cells were treated with various concentrations of NVP-BEZ235 for $12 \mathrm{~h}$. The expression of pS6 was significantly inhibited by $100 \mathrm{nM}$ NVP-BEZ235. The expression of pAkt and p4EBP1 was also significantly inhibited in a dose-dependent manner by NVP-BEZ235. (B) Western blots revealed that the expression of pAkt, pS6 and p4EBP1 was inhibited within $12 \mathrm{~h}$ of exposure of MBT-2 cells to $1000 \mathrm{nM}$ NVP-BEZ235, and these inhibitory effects persisted for $24 \mathrm{~h}$.

\section{Bladder weights $(\mathrm{g})$}

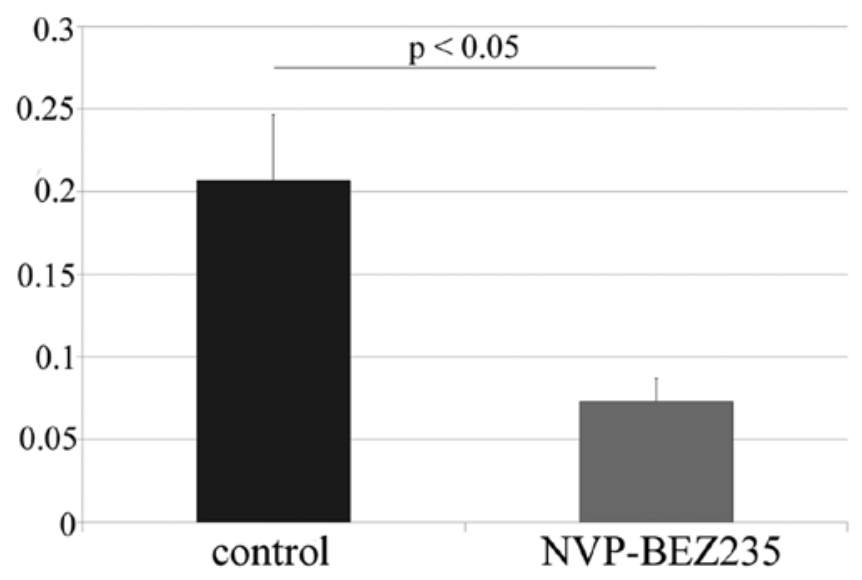

Figure 3. After the MBT-2 orthotopic bladder tumor model had been established, $100 \mu 1$ of PBS or $40 \mu \mathrm{M}$ of NVP-BEZ235 in $100 \mu 1$ of PBS was instilled transurethrally ( $\mathrm{n}=15$ mice per group). Instillations were carried out 5 times at 3-day intervals starting 5 days after tumor implantation. Mice were sacrificed on day 21 , and the weights of their bladders were measured to assess the growth of bladder tumors. Bladder weights were significantly lower in the intravesical NVP-BEZ235 therapy in situ group than in the control group $(\mathrm{P}=0.0038)$.

Therapeutic effects of intravesical NVP-BEZ235 in an orthotopic bladder cancer model. Five days after the intravesical implantation of MBT-2 cells, PBS (vehicle control) or NVP-BEZ235 (40 $\mu \mathrm{M}, 18.78 \mathrm{mg} / \mathrm{l})$ was administered intravesically into mouse bladders on days 5, 8, 11, 14 and 17. All mice tolerated the 5 instillations of PBS or NVP-BEZ235 well. The mice were sacrificed on day 21 , and the weights of their bladders were ascertained to assess the growth of bladder tumors ( $n=15$ in each group). Fig. 3 shows that bladder weights were significantly lower in the intravesical NVP-BEZ235 therapy in situ group $(72.8 \pm 54.5 \mathrm{mg})$ than in the control group (206.6 $\pm 154.9 \mathrm{mg} ; \mathrm{P}=0.0038$ ).

The serum concentrations of albumin, total bilirubin, creatinine, and alanine aminotransferase on day 21 were all within normal ranges in the 2 groups, which indicated that intravesical NVP-BEZ235 therapy did not result in any systemic side effects. We also analyzed the histological appearances of the major organs, including the liver, kidneys, heart and lungs.

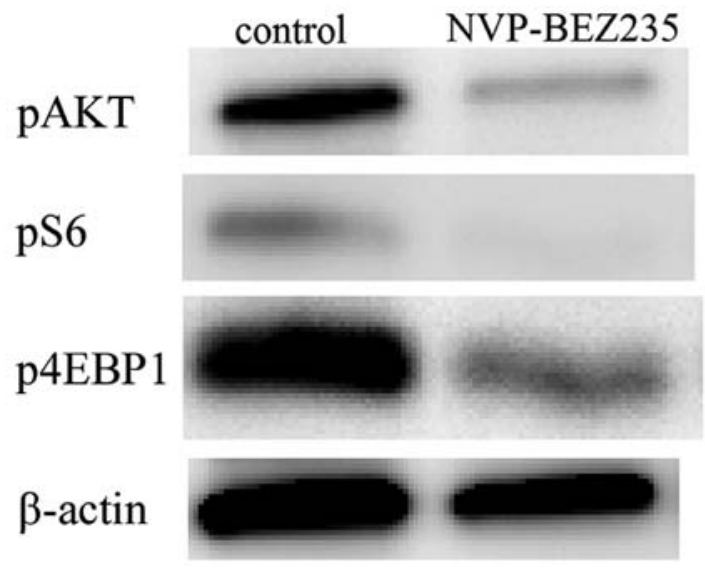

Figure 4. Mice treated with NVP-BEZ235 $(40 \mu \mathrm{M})$ or vehicle control were sacrificed $12 \mathrm{~h}$ after the last dose (on day 18). The tumors were then recovered and analyzed using western blotting to determine the protein expression of pAkt, pS6, and p4EBP1. An analysis of the tumor tissues revealed that the NVP-BEZ235 treatment strongly reduced the expression of pAkt, pS6 and p4EBP1.

Staining with hematoxylin and eosin showed that there were no significant differences in the histological appearances of or damage to the major organs of the control or NVP-BEZ235treated mice.

Analysis of orthotopic MBT-2 tumor tissues by western blotting. Mice treated with vehicle control or NVP-BEZ235 were sacrificed $12 \mathrm{~h}$ after the last dose. The tumors were then removed and analyzed using western blotting for pAkt, pS6, and p4EBP1. The analysis of MBT-2 tumors indicated that pAkt, pS6, and p4EBP1 signaling was markedly lower in tumors treated with NVP-BEZ235 than in those treated with vehicle control (Fig. 4). This result demonstrated that, in the orthotopic bladder cancer model, the intravesical NVP-BEZ235 treatment inhibited elevations in pAkt and downstream targets (pS6 and p4EBP1) in bladder cancer tissues.

Immunohistochemical analysis of tumor tissues. pS6 immunostaining on tumor tissue was evaluated in mice treated with NVP-BEZ235 or vehicle control. The expression of the pS6 protein was significantly lower in bladder tumor tissue treated 

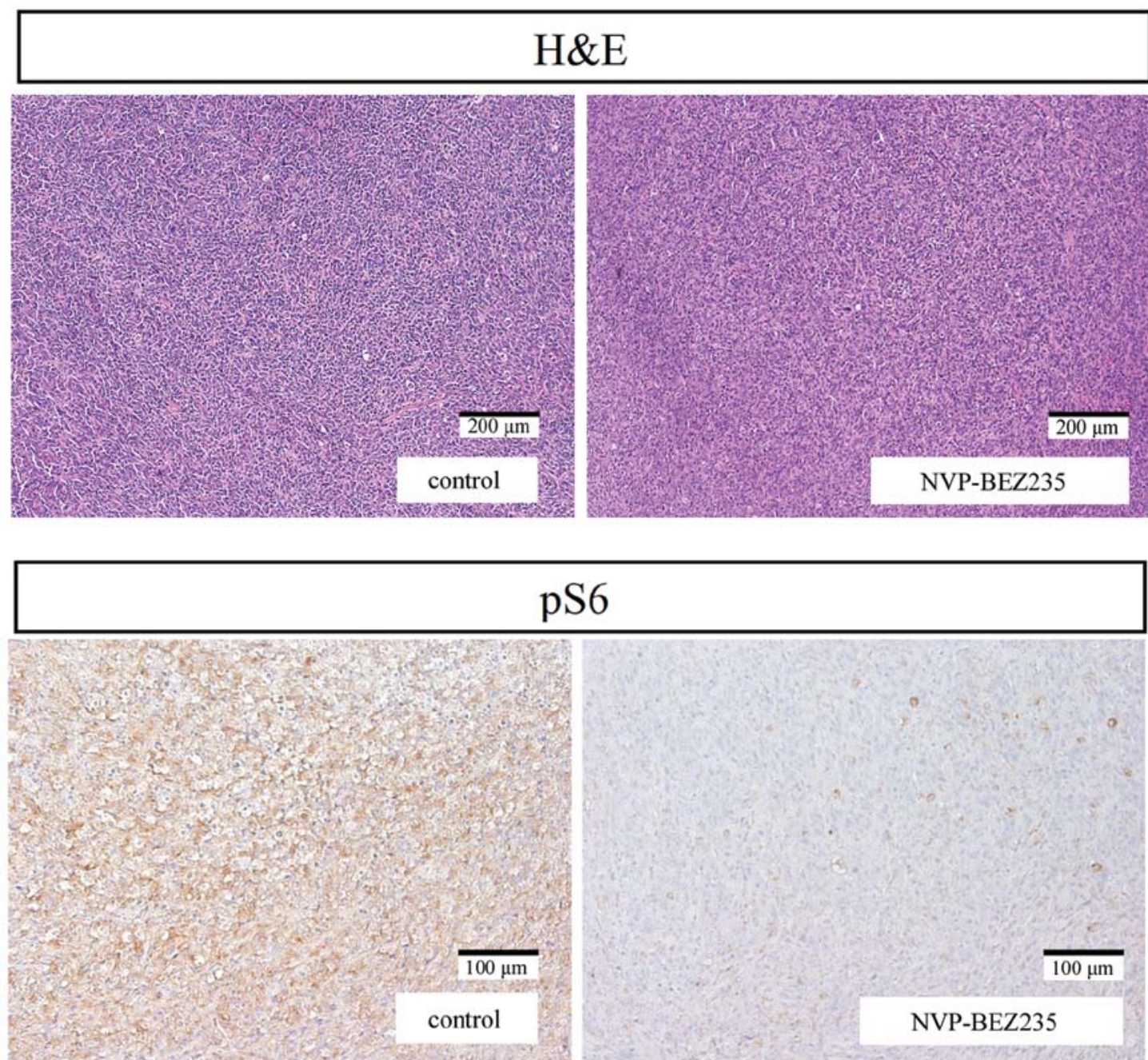

Figure 5. Starting 5 days after the implantation of MBT-2 tumor cells, NVP-BEZ235 (40 $\mu \mathrm{M})$ was instilled into the bladder (on days 5, 8 , 11, 14 and 17). The animals were sacrificed $12 \mathrm{~h}$ after the last dose. Immunohistochemical staining of the representative tumor tissue sections obtained was carried out after the treatment with NVP-BEZ235 or vehicle control. The expression of pS6 was significantly inhibited by NVP-BEZ235.

with NVP-BEZ235 than in the tissue treated with vehicle control (Fig. 5).

\section{Discussion}

In the present study, the cytotoxic effects of NVP-BEZ235 were observed in MBT-2 tumor cells in vitro through the inhibition of pAkt protein expression, as well as the downstream targets of pS6 and p4EBP1. Furthermore, the intravesical NVP-BEZ235 therapy had significant inhibitory effects on tumor growth in the MBT-2 orthotopic bladder cancer model. An analysis of tumor tissues by western blotting revealed that the NVP-BEZ235 treatment strongly reduced the expression of pAkt, pS6, and p4EBP1. An immunohistochemical analysis revealed that the expression of pS6 was significantly inhibited by the intravesical instillation of NVP-BEZ235. These results indicated that targeting the PI3K/Akt/mTOR pathway with NVP-BEZ235 had a strong cytotoxic effect on bladder tumors; therefore, the intravesical administration of NVP-BEZ235 may represent a novel therapeutic modality for NMIBC.

The PI3K/Akt/mTOR pathway has attracted significant interest among UC researchers because the clinical importance of members of the PI3K/Akt/mTOR signaling pathway in UC has been demonstrated in previous studies (22-26). The expression of various PI3K/Akt/mTOR signaling pathway members including p-mTOR, pAkt and p4EBP1 was shown to be higher in UCs than in normal urothelia $(24,25)$. Korkolopoulou et al (24) reported that the cytoplasmic expression levels of p-mTOR and pAkt in UCs were higher than those in normal urothelia. Several studies have also shown that the expression of various PI3K/Akt/mTOR signaling pathway members (p-mTOR, pS6 and pAkt) correlated positively with higher grades and/or stages $(23,25,26)$. Sun et al $(26)$ demonstrated that the expression of pS6 and pAkt correlated positively with higher grades in 887 cases of bladder cancer. Furthermore, recent studies reported that the expression levels of p-mTOR, pS6, and p4EBP1 were independent prognostic factors of bladder cancer-specific survival (CSS) (23-26). The strong expression of pS6 was previously shown to predict shorter recurrence-free survival, especially in patients with NMIBC $(22,25)$. These findings indicated that upregulating the PI3K/Akt/mTOR pathway may be strongly associated with tumor aggressiveness, invasion and survival in patients with UC. 
Previous preclinical studies reported that rapamycin and its derivative RAD001, reduced cancer cell viability and decreased the expression of PI3K/Akt/mTOR signaling pathway members such as p-mTOR, pS6, p4EBP1 and p-p70S6K in bladder cancer cell lines (11-14). The effects of inhibiting mTORC1 on bladder tumor growth have also been reported in a xenograft mouse model $(11,13,14)$. Only one previous study on intravesical mTOR inhibitor therapy used the mTORC1 inhibitor rapamycin (27). They demonstrated that this therapy successfully suppressed bladder tumorigenesis, and subsequently concluded that the inhibition of mTOR signaling may have potential therapeutic benefits for patients at high risk of developing invasive bladder cancer. However, Vasconcelos-Nóbrega et al (28) recently reported that RAD001 only exerted modest effects in a chemically-induced UC animal model. Furthermore, clinical phase II trials on metastatic UC using temsirolimus, an inhibitor of mTORC1, failed to demonstrate any clinical activity (29). These controversial findings for mTORC1 inhibitors suggest the existence of mechanisms that result in rapamycin resistance. mTORC2 is considered to be regulated by rapamycin and activates the Akt signal pathway. This Akt-driven feedback loop has been identified as one of the mechanisms by which resistance to mTORC1 inhibitors develops $(30,31)$. Thus, the inhibition of not only mTORC1, but also mTORC2 may be required to achieve a significant clinical effect (17).

mTORC2 is known to control processes that involve cytoskeletal remodeling, such as cell spreading and migration, in several cancers including UC (32). One study demonstrated that increased mTORC2 activity was associated with bladder cancer invasion that was primarily mediated through Racl as a major downstream target of mTORC2 (32). In the present study, we speculated that the dual inhibition of PI3K and mTORC1/2 may have strong therapeutic effects on bladder tumors in vivo and, thus, investigated the inhibitory effects of NVP-BEZ235, which is a novel dual PI3K and mTORC1/2 inhibitor, on orthotopic bladder tumors through an intravesical administration protocol. Several preclinical studies have reported promising activities for NVP-BEZ235 against various tumors $(16,17)$, and various phase $1 / 2$ clinical trials on NVP-BEZ235 as a breast cancer treatment are now being performed in different countries. We demonstrated that NVP-BEZ235 effectively blocked the PI3K/Akt/mTOR pathway and reduced tumor growth in the MBT-2 orthotopic bladder cancer model. To the best of our knowledge, intravesical dual PI3K and mTORC1/2 inhibitor therapy has not previously been assessed using an orthotopic bladder cancer model. Although no clinical trial has examined the effects of NVP-BEZ235 in UC patients, the experimental data generated in the present study strongly support the potential clinical application of this strategy in the future.

It is important to recognize that when tumor cells are removed from their natural milieu, they behave differently from those in the organ of origin $(33,34)$. The orthotopic bladder cancer model used in the present study closely mimics the clinical situation, and has consequently helped to shed light on the mechanisms involved, which is a prerequisite for drawing meaningful conclusions (35). Various orthotopic bladder cancer models have been described; however, limitations have been associated with all these models, including low rates of tumor implantation and damage to the urothelium as a result of electrocautery or the application of chemical agents to facilitate tumor uptake, which induces the tumors to become invasive $(36,37)$. The incidence of tumor establishment was high in our model following the simple instillation of MBT-2 cell suspensions into the bladders of syngeneic hosts (18). Our model was easily established by different investigators working in different institutions, is highly reproducible, and avoids the need for any open surgical procedures for implantation. The model can also be used to evaluate new intravesical agents against bladder tumors in situ. IL-2, IL-12 and IL-15 intravesical gene therapies have previously been examined by our group using this model (19-21).

Although the toxicity of NVP-BEZ235 remains unknown, the systemic absorption of agents rarely occurs through intravesical administration. The intravesical instillation of biological and chemotherapeutic agents facilitates the direct access of these agents to the bladder mucosa and tumor (38). Therefore, a distinct benefit of this localized approach is that agents can be used at high doses with a minimal risk of systemic adverse effects (39). The intravesical NVP-BEZ235 therapy did not cause any systemic side effects in our study.

In conclusion, we herein demonstrated that intravesically administered NVP-BEZ235 therapy exhibited therapeutic effects in the MBT-2 orthotopic bladder cancer model by inhibiting the $\mathrm{PI} 3 \mathrm{~K} / \mathrm{Akt} / \mathrm{mTOR}$ signaling pathway. This administration route is unique. The results obtained in the present study provide molecular-level evidence that supports the clinical use of a dual $\mathrm{PI} 3 \mathrm{~K}$ and $\mathrm{mTORC} 1 / 2$ inhibitor and may indicate that this is a useful approach for treating patients with bladder cancer.

\section{Acknowledgements}

The study was supported in part by Grants-in Aid for Scientific Research (KAKENHI, no. 25861450) from the Ministry of Education, Science, Sports, Culture and Technology of Japan.

\section{References}

1. Hsieh JT, Dinney CP and Chung LW: The potential role of gene therapy in the treatment of bladder cancer. Urol Clin North Am 27: 103-113, ix, 2000.

2. Stein JP and Skinner DG: Radical cystectomy for invasive bladder cancer: Long-term results of a standard procedure. World J Urol 24: 296-304, 2006.

3. Böhle A and Brandau S: Immune mechanisms in bacillus Calmette-Guerin immunotherapy for superficial bladder cancer. J Urol 170: 964-969, 2003.

4. Alexandroff AB, Jackson AM, O'Donnell MA and James K: BCG immunotherapy of bladder cancer: 20 years on. Lancet 353 : 1689-1694, 1999.

5. Bai X and Jiang Y: Key factors in mTOR regulation. Cell Mol Life Sci 67: 239-253, 2010.

6. Engelman JA: Targeting PI3K signalling in cancer: Opportunities, challenges and limitations. Nat Rev Cancer 9: 550-562, 2009.

7. Courtney KD, Corcoran RB and Engelman JA: The PI3K pathway as drug target in human cancer. J Clin Oncol 28: 1075-1083, 2010.

8. Seeliger H, Guba M, Kleespies A, Jauch KW and Bruns CJ: Role of mTOR in solid tumor systems: A therapeutical target against primary tumor growth, metastases, and angiogenesis. Cancer Metastasis Rev 26: 611-621, 2007.

9. Abe H and Kamai T: Recent advances in the treatment of metastatic renal cell carcinoma. Int J Urol 20: 944-955, 2013.

10. Wada Y, Takahashi W, Kawano Y and Eto M: Current status of pharmacotherapy against metastatic renal cell carcinoma in Japan. Int J Urol 19: 284-295, 2012.

11. Chiong E, Lee IL, Dadbin A, Sabichi AL, Harris L, Urbauer D, McConkey DJ, Dickstein RJ, Cheng T and Grossman HB: Effects of mTOR inhibitor everolimus (RAD001) on bladder cancer cells. Clin Cancer Res 17: 2863-2873, 2011. 
12. Fechner G, Classen K, Schmidt D, Hauser S and Müller SC: Rapamycin inhibits in vitro growth and release of angiogenetic factors in human bladder cancer. Urology 73: 665-668, discussion 668-669, 2009

13. Makhlin I, Zhang J, Long CJ, Devarajan K, Zhou Y, KleinSzanto AJ, Huang M, Chernoff J and Boorjian SA: The mTOR pathway affects proliferation and chemosensitivity of urothelial carcinoma cells and is upregulated in a subset of human bladder cancers. BJU Int 108: E84-E90, 2011.

14. Mansure JJ, Nassim R, Chevalier S, Rocha J, Scarlata E and Kassouf W: Inhibition of mammalian target of rapamycin as a therapeutic strategy in the management of bladder cancer Cancer Biol Ther 8: 2339-2347, 2009.

15. Serra V, Markman B, Scaltriti M, Eichhorn PJ, Valero V, Guzman M, Botero ML, Llonch E, Atzori F, Di Cosimo S, et al: NVP-BEZ235, a dual PI3K/mTOR inhibitor, prevents PI3K signaling and inhibits the growth of cancer cells with activating PI3K mutations. Cancer Res 68: 8022-8030, 2008.

16. Cho DC, Cohen MB, Panka DJ, Collins M, Ghebremichael M, Atkins MB, Signoretti S and Mier JW: The efficacy of the novel dual PI3-kinase/mTOR inhibitor NVP-BEZ235 compared with rapamycin in renal cell carcinoma. Clin Cancer Res 16: 3628-3638, 2010

17. Maira SM, Stauffer F, Brueggen J, Furet P, Schnell C, Fritsch C, Brachmann $\mathrm{S}$, Chène $\mathrm{P}$, De Pover $\mathrm{A}$, Schoemaker $\mathrm{K}$, et al: Identification and characterization of NVP-BEZ235, a new orally available dual phosphatidylinositol 3-kinase/mammalian target of rapamycin inhibitor with potent in vivo antitumor activity. Mol Cancer Ther 7: 1851-1863, 2008.

18. Horiguchi Y, Kikuchi E, Ozu C, Nishiyama T, Oyama M, Horinaga M, Yoshioka K and Tachibana M: Establishment of orthotopic mouse superficial bladder tumor model for studies on intravesical treatments. Hum Cell 21: 57-63, 2008.

19. Horiguchi Y, Larchian WA, Kaplinsky R, Fair WR and Heston WD: Intravesical liposome-mediated interleukin-2 gene therapy in orthotopic murine bladder cancer model. Gene Ther 7: 844-851, 2000.

20. Horinaga M, Harsch KM, Fukuyama R, Heston W and Larchian W: Intravesical interleukin-12 gene therapy in an orthotopic bladder cancer model. Urology 66: 461-466, 2005.

21. Matsumoto K, Kikuchi E, Horinaga M, Takeda T, Miyajima A, Nakagawa $\mathrm{K}$ and Oya $\mathrm{M}$ : Intravesical interleukin-15 gene therapy in an orthotopic bladder cancer model. Hum Gene Ther 22: 1423-1432, 2011

22. Fahmy M, Mansure JJ, Brimo F, Yafi FA, Segal R, Althunayan A, Hicks J, Meeker A, Netto G and Kassouf W: Relevance of the mammalian target of rapamycin pathway in the prognosis of patients with high-risk non-muscle invasive bladder cancer. Hum Pathol 44: 1766-1772, 2013

23. Hansel DE, Platt E, Orloff M, Harwalker J, Sethu S, Hicks JL, De Marzo A, Steinle RE, Hsi ED, Theodorescu D, et al: Mammalian target of rapamycin (mTOR) regulates cellular proliferation and tumor growth in urothelial carcinoma. Am J Pathol 176: 3062-3072, 2010

24. Korkolopoulou P, Levidou G, Trigka EA, Prekete N, Karlou M, Thymara I, Sakellariou S, Fragkou P, Isaiadis D, Pavlopoulos P, et al: A comprehensive immunohistochemical and molecular approach to the PI3K/AKT/mTOR (phosphoinositide 3-kinase/v-akt murine thymoma viral oncogene/mammalian target of rapamycin) pathway in bladder urothelial carcinoma. BJU Int 110: E1237-E1248, 2012.
25. Park SJ, Lee TJ and Chang IH: Role of the mTOR pathway in the progression and recurrence of bladder cancer: An immunohistochemical tissue microarray study. Korean J Urol 52: 466-473, 2011.

26. Sun $\mathrm{CH}$, Chang YH and Pan CC: Activation of the PI3K/Akt/ mTOR pathway correlates with tumour progression and reduced survival in patients with urothelial carcinoma of the urinary bladder. Histopathology 58: 1054-1063, 2011.

27. Seager CM, Puzio-Kuter AM, Patel T, Jain S, Cordon-Cardo C, McKiernan J and Abate-Shen C: Intravesical delivery of rapamycin suppresses tumorigenesis in a mouse model of progressive bladder cancer. Cancer Prev Res (Phila) 2: 1008-1014, 2009.

28. Vasconcelos-Nóbrega C, Pinto-Leite R, Arantes-Rodrigues R, Ferreira R, Brochado P, Cardoso ML, Palmeira C, Salvador A, Guedes-Teixeira CI, Colaço A, et al: In vivo and in vitro effects of RAD001 on bladder cancer. Urol Oncol 31: 1212-1221, 2013.

29. Gerullis H, Eimer C, Ecke TH, Georgas E, Freitas C, Kastenholz S, Arndt C, Heusch C and Otto T: A phase II trial of temsirolimus in second-line metastatic urothelial cancer. Med Oncol 29: 2870-2876, 2012.

30. Carracedo A, Ma L, Teruya-Feldstein J, Rojo F, Salmena L, Alimonti A, Egia A, Sasaki AT, Thomas G, Kozma SC, et al: Inhibition of mTORC1 leads to MAPK pathway activation through a PI3K-dependent feedback loop in human cancer. J Clin Invest 118: 3065-3074, 2008.

31. O'Reilly KE, Rojo F, She QB, Solit D, Mills GB, Smith D, Lane H, Hofmann F, Hicklin DJ, Ludwig DL, et al: mTOR inhibition induces upstream receptor tyrosine kinase signaling and activates Akt. Cancer Res 66: 1500-1508, 2006.

32. Gupta S, Hau AM, Beach JR, Harwalker J, Mantuano E, Gonias SL, Egelhoff TT and Hansel DE: Mammalian target of rapamycin complex 2 (mTORC2) is a critical determinant of bladder cancer invasion. PLoS One 8: e81081, 2013.

33. Connor J, Bannerji R, Saito S, Heston W, Fair W and Gilboa E: Regression of bladder tumors in mice treated with interleukin 2 gene-modified tumor cells. J Exp Med 177: 1127-1134, 1993.

34. Fidler IJ: Critical factors in the biology of human cancer metastasis: Twenty-eighth G.H.A. Clowes memorial award lecture. Cancer Res 50: 6130-6138, 1990.

35. Ratliff TL: Role of animal models in understanding intravesical therapy with bacille Calmette-Guérin. Clin Infect Dis 31 (Suppl 3): S106-S108, 2000.

36. Chin J, Kadhim S, Garcia B, Kim YS and Karlik S: Magnetic resonance imaging for detecting and treatment monitoring of orthotopic murine bladder tumor implants. J Urol 145: 1297-1301, 1991.

37. Weldon TE and Soloway MS: Susceptibility of urothelium to neoplastic cellular implantation. Urology 5: 824-827, 1975.

38. Hsu CC, Chuang YC and Chancellor MB: Intravesical drug delivery for dysfunctional bladder. Int J Urol 20: 552-562, 2013.

39. Dalbagni G, Russo P, Sheinfeld J, Mazumdar M, Tong W, Rabbani F, Donat MS, Herr HW, Sogani P, dePalma D, et al: Phase I trial of intravesical gemcitabine in bacillus CalmetteGuérin-refractory transitional-cell carcinoma of the bladder. J Clin Oncol 20: 3193-3198, 2002. 